\title{
Labour Productivity in the Hotel Business
}

\section{by \\ W. H. M. Van der Hoeven and A. R. Thurik*}

This article studies differences in labour productivity in the hotel business. Cross section data consisting of one German and two Dutch samples are used. Explanatory variables are: scale, proportion of restaurant sales relative to accommodation sales, wage rate, location and price. This analysis is part of a larger fundamental quantitative study of the explanation of productivity differences in the hospitality business.

\section{INTRODUCTION}

A linear relationship between the volume of labour and value of annual sales was found for reasonably homogeneous samples of the hotel and catering business in an earlier study on grouped data [Van der Hoeven, 1982]. In the present study a relationship to explain the volume of labour is investigated using data from individual hotels. Labour productivity is shown to depend on value of annual sales, composition of sales, wage rate, location and the luxury level of the establishments. Quantitative estimations of the intensity of these dependencies are given. In the following section the basic concepts of the labour costs studies in retailing are given, while in section 3 the conversion to the hotel sector is made. In section 4 the hypotheses to be tested are formulated and in section $5 \mathrm{a}$ description of the data is given. Section 6 contains the explanation of the test models. Results of the tests and conclusions are given in sections 7 and 8 .

\section{BASIC CONCEPTS}

A relationship between the volume of labour and value of annual sales has been developed by Nooteboom for retail establishments of a certain

\footnotetext{
*This study benefits greatly from the extensive studies in retailing performed at the Research Institute for Small and Medium Sized Businesses, Zoetermeer, The Netherlands. The authors are also indebted to the CBS (Central Bureau of Statistics in The Netherlands) and DWIF (Deutsches Wirtschaftswissenschaftliches Institut für Fremdenverkehr an der Universität München in Germany), which have made this research possible by providing
data.
} 
shop type. ${ }^{1}$ This study will be based on this relationship, for the following reasons.

(1) There is a certain similarity between the hospitality business and retailing. Firstly, they both provide service capacity. ${ }^{2}$ Therefore, the concept of threshold labour may also be relevant in the hotel business. Secondly, two types of labour can also be discerned in the hospitality business (labour to serve customers and labour for other activities). Thirdly, some principal arguments of the theoretical justification (concerning queueing theory) are assumed to apply also to groups of establishments in the hospitality business.

(2) Encouraging results were obtained in an earlier study [Van der Hoeven, 1982] on grouped data of reasonably homogeneous samples in the hotel and catering business: the linearity of the relationship between the volume of labour and the value of annual sales could not be rejected and positive thresholds (intercepts) were found.

(3) The relationship appears to have a very wide applicability."

(4) In its basic form it is simple and scale effects are studied easily.

Thurik [1984] uses the following specification for his empirical research purposes for large shop types carrying more than one assortment group:

$$
\begin{aligned}
& \mathrm{L}_{\mathrm{i}}=\sum_{\mathrm{k}=1}^{\mathrm{K}} \alpha_{\mathrm{ok}}+\sum_{\mathrm{k}=1}^{\mathrm{K}} \alpha_{1 \mathrm{ki}} \mathrm{Q}_{\mathrm{ki}} \text { with } \alpha_{\mathrm{ok}}>0 \text { and } \alpha_{\mathrm{jki}}>0 \\
& \text { for } \mathrm{k}=1,---, \mathrm{K},
\end{aligned}
$$

where:

$\mathrm{L}_{\mathrm{i}}=$ volume of labour in establishment $\mathrm{i}$;

$\mathrm{Q}_{\mathrm{ki}}=$ value of annual sales in assortment group $\mathrm{k}$ in establishment $\mathrm{i}$;

$\mathrm{K}=$ total number of assortment groups in the shop type considered;

$\alpha_{o k}=$ threshold labour of assortment group $k$. Its value is associated with the number of independently staffed departments and their annual opening times (see Nooteboom [1982]).

Clearly,

$$
\sum_{\mathrm{k}=1}^{\mathrm{K}} \mathrm{Q}_{\mathrm{ki}} \stackrel{\triangle}{=} \mathrm{Q}_{\mathrm{i}}
$$

where $Q_{i}$ is the value of annual sales of establishment $i$.

Equation (2.1) is equivalent to

$$
\mathrm{L}_{\mathrm{ki}}=\alpha_{0 \mathrm{k}}+\alpha_{1 \mathrm{ki}} \mathrm{Q}_{\mathrm{ki}} \text { with } \mathrm{L}_{\mathrm{i}}=\sum_{\mathrm{k}=1}^{\mathrm{K}} \mathrm{L}_{\mathrm{ki}} \text {. }
$$

$\alpha_{1 \mathrm{ki}}$ is called partial scale adjusted labour intensity (partial sli). This terminology becomes clear after rewriting (2.3): 


$$
\frac{\mathrm{L}_{\mathrm{ki}}}{\mathrm{Q}_{\mathrm{ki}}}=\alpha_{1 \mathrm{ki}}+\frac{\alpha_{\mathrm{ok}}}{\mathrm{Q}_{\mathrm{ki}}} \text {. }
$$

Thus, labour intensity per assortment group (i.e. partial) can be subdivided into a scale dependent part $\frac{\alpha_{\mathrm{ok}}}{\mathrm{Q}_{\mathrm{ki}}}$, and into a scale independent part $\alpha_{1 \text { ki }}$.

Note the use of index $\mathrm{i}$ in $\alpha_{1 \mathrm{ki}}$ : the values of the partial sli's depend on specific properties of establishment $i$. These properties are associated with type of labour, type of product, method of service, method of shop operation, characteristics of demand, and so on. In addition, the equivalence of (2.1) and (2.3) means that a large establishment is considered to be a system of several independent small shops as far as the use of labour is concerned. ${ }^{4}$ Relationship (2.1) will be used in the present study to analyse differences in labour productivity for samples of establishments of the hotel business, because the value of annual sales of hotels can also be subdivided in different sales fractions.

\section{HOTEL BUSINESS}

There are large differences in the service package offered by the establishments of the hotel samples studied here. As far as the composition of sales is concerned, accommodation sales, restaurant sales and other sales are discerned, and special attention is paid in this study to the influence of this sales composition on labour productivity.

Inter-firm comparative surveys show that with increasing size of the establishments, the service package offered changes in the sense that service level becomes more extended. ${ }^{5}$ The number of service channels is likely to increase with size, an assumption which is supported by empirical results [Van der Hoeven, 1982]. Therefore, threshold labour is assumed to be influenced by the grading (or luxury level) of the establishment, while its influence on the scale adjusted labour intensities is assumed to be incorporated by the influence of other establishment characteristics (see section 4). As a consequence, equation (2.1) will be adapted in the following way:

$$
\mathrm{L}_{\mathrm{i}}=\sum_{\mathrm{h}=1}^{\mathrm{H}} \alpha_{\mathrm{oh}}+\sum_{\mathrm{k}=1}^{\mathrm{K}} \alpha_{1 \mathrm{ki}} \mathrm{Q}_{\mathrm{ki}} \text { with } \alpha_{\mathrm{oh}}>\mathrm{o} \text { for } \mathrm{h}=1,---, \mathrm{H},
$$

where:

$\mathrm{h}=$ refers to the luxury classes: an increasing value of $\mathrm{h}$ indicates an increasing luxury class;

$\mathbf{H}=$ total number of luxury classes;

$\alpha_{o 1}=$ basic threshold labour;

$\alpha_{\mathrm{oh}}=$ additional threshold labour associated with luxury class $h$, for $\mathrm{h}=2,---, \mathrm{H}$;

$\mathrm{K}=$ total number of sales fractions: in our study $\mathrm{K}=3$, viz. for accommodation, restaurant and other sales. 
Using equation (3.1) as a maintained hypothesis, the following hypotheses will be tested.

H1: Economies of scale can be achieved concerning the use of labour, i.e. $\quad \mathbf{H}$

$$
\sum_{h=1} \alpha_{\mathrm{oh}}>0 \text {. }
$$

H2: Threshold labour depends on the luxury class of the establishment, in that it increases if the luxury level increases, i.e. $\alpha_{o h}>0$ for $h=2,---, H$.

H3: Different sales fractions have different partial scale adjusted labour intensities $\alpha_{1 \mathrm{ki}}$ for $\mathrm{k}=1,2,3$.

It would be interesting to state hypotheses concerning the relative values of the different partial sli's; from our previous studies no conclusion can be made. However, it is found in inter-firm comparative surveys that the pay-roll costs allocated to the restaurant department are higher than those allocated to the accommodation department: room sales involve less pay-roll costs than food and beverage sales. Assuming that the average wage rates are approximately equal for the accommodation and restaurant department, a higher sli can be expected for the restaurant sales than for the accommodation department.

Hypotheses about the influence of other specific properties of the establishments on the sli's are discussed in the next section.

\section{FURTHER HYPOTHESES}

In this section the influence of specific properties of the establishment will be discussed. The choice of the properties is based on the availability of the data.

\section{Wage rate ${ }^{7}$}

Firstly, it is assumed that the wage rate per establishment is an indicator of the quality of labour used. Secondly, a high price of labour is assumed to stimulate efficient utilisation of available labour. Generally, labour intensity may be reduced through improvements in the quality of labour employed and by using better management [Kotas, 1975].

H4: Scale adjusted labour intensity decreases if the wage rate of the establishment increases.

\section{Type of hotel}

In one of the investigated samples a distinction is made between town hotels and holiday hotels (resort hotels). It appears from the data that the average length of stay is much longer in the resort hotels than in the town hotels. Longer average lengths of stay involve less labour per value unit of sales, because considerable labour is required by departures and arrivals of residents. Moreover, the amount of required labour in resort hotels is assumed to be better known in advance, which allows for better planning and labour saving. 
H5: Scale adjusted labour intensity is assumed to be lower in a resort hotel than in a town hotel.

\section{Luxury level of the hotel}

There are differences in the luxury level of establishments within the group of hotels of the same luxury class. The amount of labour per value unit of sales is assumed to increase with the luxury level of the hotel. Price difference of an overnight stay is assumed to be a proxy variable for the luxury class, because price serves as a good indicator of quality. ${ }^{B}$

H6: The scale adjusted labour intensity increases when the luxury level of the establishment increases.

\section{DATA}

For this study use was made of data from an inter-firm comparative survey of hotels in 1979. The survey was undertaken by the DWIF (Deutsches Wirtschaftswissenschaftliches Institut für Fremdenverkehr an der Universität München). The reader is referred to the Hotel Betriebsvergleich 1979 for an extensive description of these data. The sample consists of individual data of 132 hotels in 1979 [Maschke, 1981]. Labour is recorded in full-time equivalents. Distinction is made between town hotels (Stadthotels) and resort hotels (Ferien- und Kur-hotels). In the explanatory notes of Maschke's publication, special attention is given to the quality level of the establishment. The following criteria are considered:

(a) the furnishings in the rooms (furniture and sanitary facilities);

(b) the image and reputation of the hotel;

(c) the price level.

The establishments are grouped in the following classes.

Class 1: Establishments of the standard level with standard furnishings.

Class 2: Establishments with better than standard furnishings and whose quality level of all services provided is more than average. Establishments in this class also provide conference and/or sports amenities. The higher qualification is also expressed in the price level.

Class 3: Establishments with first class furnishings. These establishments belong to the best hotels of the location concerning quality and image, and the equipment and services provided are for a selected group of customers only.

Use is also made of Produktiestatistieken Commerciële Dienstverlening Hotels 1977 (Production Statistics Commercial Services) from the Central Bureau of Statistics in the Netherlands [CBS, 1980]. The reader is referred to this publication for an extensive description of these data. The CBS's unit of inquiry is the enterprise. For our study, however, the unit of inquiry is the establishment [Nooteboom, 1980: 30], and therefore the 
enterprises consisting of one establishment were selected from the sample. At our request, the CBS carried out some computations on the data." The volume of labour is given in full-time equivalents in this sample, as in the German data.

For the CBS sample no description of the luxury level is available. Therefore, it is assumed that sales size influences the volume of threshold labour, because the establishments with a higher value of sales are assumed to belong to a higher class [Van der Hoeven, 1982]. This influence will be represented using a dummy variable. Special care had to be given to the computation of the wage rate in the Dutch samples, because different legal structures occur: limited liability companies where the manager-owner receives wages like the rest of the persons engaged, and family businesses where the owner is not on the payroll. Separate estimations are performed for these two groups of establishments, because the computation of the wage rate differs. For the family businesses the wage rate had to be approximated. ${ }^{10}$ In the remainder of this paper limited liability companies are indicated by NV, and family businesses by EE.

In contrast to the German data, the price of an overnight stay is not available. Differences of the gross profit in beverages are chosen as a proxy variable for the quality or luxury level. The price of the beverage assortment is assumed to be positively correlated with the luxury level of the establishment. The distinction between accommodation and restaurant sales differs from that made in the German data. The breakfast sales are attributed to the accommodation sales instead of the restaurant sales. ${ }^{11}$

\section{TESTS}

The hypotheses mentioned above are tested using the following specification:

$$
\begin{aligned}
\mathrm{L}_{\mathrm{i}}= & \alpha_{0}+\alpha_{o 2} \mathrm{D} 2_{\mathrm{i}}+\alpha_{03} \mathrm{D} 3_{\mathrm{i}}+\left(\alpha_{11} \mathrm{QA}_{\mathrm{i}}+\alpha_{12} \mathrm{QR}_{\mathrm{i}}+\alpha_{13} \mathrm{QO}_{\mathrm{i}}\right) \times \\
& \times \exp \left(\alpha_{4} \mathrm{DL} \mathrm{L}_{\mathrm{i}}\right)\left[\frac{\mathrm{LAB}_{\mathrm{i}}}{\overline{\mathrm{L}} \overline{\mathrm{A}} \overline{\mathrm{B}}}\right]^{\alpha_{5}}\left[\frac{\mathrm{LU}_{\mathrm{i}}}{\overline{\mathrm{L}} \overline{\mathrm{U}}}\right]^{\alpha_{6}}+v_{\mathrm{i}},
\end{aligned}
$$

where

$\mathrm{L}_{\mathrm{i}} \quad=$ the volume of labour in full-time equivalents in establishment $\mathrm{i}$;

$\mathrm{QA}_{\mathrm{i}}=$ the value of annual accommodation sales (Beherbergung);

$\mathrm{QR}_{\mathrm{i}}=$ the value of annual restaurant sales or that of food and beverages (Küche und Keller);

$\mathrm{QO}_{\mathrm{i}}=$ the value of annual remaining activities sales (other sales);

$\mathrm{LAB}_{\mathrm{i}}=$ the wage rate per man-year (in $10^{3} \mathrm{DM}$ or DFL) per establishment $\mathrm{i}$;

$\overline{\mathrm{L}} \overline{\mathrm{A}} \overline{\mathrm{B}}=$ the sample average of $\mathrm{LAB}_{i}$;

$v_{\mathrm{i}}=$ disturbance term. $^{12}$

For the German sample:

$\mathrm{D} 2_{\mathrm{i}}=1$, if the establishment is of class 2 and $\mathrm{D} 2_{\mathrm{i}}=0$ otherwise;

$D 3_{i}=1$, if the establishment is of class 3 and $D 3_{i}=0$ otherwise; 
$\mathrm{LU}_{\mathrm{i}}=$ the price of an overnight stay;

$\overline{\mathrm{LU}}=$ the sample average of $\mathrm{LU}_{\mathrm{i}}$;

$\mathrm{DL}_{\mathrm{i}}=1$, if the establishment is a resort hotel and $\mathrm{DL}_{\mathrm{i}}=0$ otherwise (if the establishment is a town hotel).

For the Dutch samples:

$\mathrm{D} 2_{\mathrm{i}}=1$, if the value of annual sales is larger than $10^{6} \mathrm{DFL}$ and $\mathrm{D} 2_{\mathrm{i}}=0$ otherwise;

$\mathrm{LU}_{\mathrm{i}}=$ the gross profit on beverages sold;

$\mathrm{D}_{\mathrm{i}}=0$ and $\mathrm{DL}_{\mathrm{i}}=0$ in all cases.

Comparing equation (3.1) and (6.1), it is seen that

$$
\sum_{h=1}^{H} \alpha_{o h}=\alpha_{o}+\alpha_{o 2} D 2_{i}+\alpha_{o, 3} D 3_{i}
$$

and

$$
\alpha_{1 \mathrm{ki}}=\alpha_{1 \mathrm{k}} \exp \left(\alpha_{4} \mathrm{DL}_{\mathrm{i}}\right) \times\left[\frac{\mathrm{LAB}_{\mathrm{i}}}{\overline{\mathrm{L}} \overline{\mathrm{A}} \overline{\mathrm{B}}}\right]^{\alpha_{5}} \times\left[\frac{\mathrm{LU}_{\mathrm{i}}}{\overline{\mathrm{L}} \overline{\mathrm{U}}}\right]^{\alpha_{6}}
$$

for $\mathrm{k}=1,2,3$.

The multiplicative specification for $\alpha_{1 \mathrm{ki}}$ is chosen because such a specification accounts for interaction of the influences of the respective variables. The influence of these variables is assumed equal for all three sales groups. This assumption is made for convenience. Clearly, the linearity of our basic relation disappears as a consequence of the multiplicative specification for $\alpha_{1 \mathrm{ki}}$.

The interpretation of the coefficients of (6.1) is:

$\alpha_{o}$

$\alpha_{02}$

$\alpha_{03}$

$\alpha_{11}, \alpha_{12}$ and $\alpha_{13}$

$\alpha_{4}$

$\alpha_{5}$ and $\alpha_{6}$ threshold labour, involved in independently staffed service channels in a class 1 establishment;

the amount of additional threshold labour in a class 2 establishment for the German data and the amount of additional threshold labour in the larger hotels in the Dutch samples;

the amount of additional threshold labour in a class 3 establishment for the German sample;

the partial scale adjusted labour intensities of the respective sales group if $\mathrm{DL}_{\mathrm{i}}=0, \mathrm{LAB}_{\mathrm{i}}=\overline{\mathrm{L}} \overline{\mathrm{A}} \overline{\mathrm{B}}$ and $\mathrm{LU}_{\mathrm{i}}=\overline{\mathbf{L}} \overline{\mathrm{U}}$;

influence of the location of the hotel;

elasticities of $\alpha_{1 k i}$ with respect to $\frac{\mathrm{LAB}_{i}}{\overline{\mathrm{L}} \overline{\mathrm{A}} \overline{\mathrm{B}}}$ and $\frac{\mathrm{LU}_{\mathrm{i}}}{\overline{\mathrm{L}} \overline{\mathrm{U}}}$,

respectively for $\mathrm{k}=1,2,3$.

Estimation results are given in Table 1. 
TABLE 1

ESTIMATES OF COEFFICIENTS OF EQUATIONS (6.1) AND (6.4)

\begin{tabular}{|c|c|c|c|c|c|}
\hline Hotels & & German & Dutch & Dutch & Dutch \\
\hline \multirow[t]{2}{*}{ Equation } & & $(6.1)$ & $(6.1)$ & $(6.1)$ & $(6.4)$ \\
\hline & & & NV & $\mathrm{EE}$ & total \\
\hline Threshold & $\hat{\alpha}_{0}$ & $\begin{array}{r}1.23^{*} \\
(0.82)\end{array}$ & $\begin{array}{c}0.19^{*} \\
(1.03)\end{array}$ & $\begin{array}{c}0.55^{*} \\
(0.49)\end{array}$ & $\begin{array}{c}0.58^{*} \\
(0.45)\end{array}$ \\
\hline Class 2 (or the larger hotels) & $\hat{\alpha}_{\mathrm{o} 2}$ & $\begin{array}{c}3.14 \\
(0.98)\end{array}$ & $\begin{array}{c}4.58 \\
(1.46)\end{array}$ & $\begin{array}{c}5.53 \\
(1.14)\end{array}$ & $\begin{array}{c}5.92 \\
(0.86)\end{array}$ \\
\hline Class 3 & $\hat{\alpha}_{03}$ & $\begin{array}{l}10.13 \\
(1.78)\end{array}$ & & & \\
\hline Accommodation & $\hat{\alpha}_{11}$ & $\begin{array}{c}9.95 \\
(0.94)\end{array}$ & $\begin{array}{l}16.50 \\
(0.99)\end{array}$ & $\begin{array}{l}16.94 \\
(1.30)\end{array}$ & $\begin{array}{l}16.53 \\
(0.75)\end{array}$ \\
\hline Restaurant & $\hat{\alpha}_{12}$ & $\begin{array}{l}17.06 \\
(0.86)\end{array}$ & $\begin{array}{l}13.93 \\
(0.96)\end{array}$ & $\begin{array}{l}13.29 \\
(1.28)\end{array}$ & $\begin{array}{l}11.92 \\
(0.58)\end{array}$ \\
\hline Other sales & $\hat{\alpha}_{13}$ & $\begin{array}{l}12.59 \\
(3.07)\end{array}$ & $\begin{array}{c}1.51^{*} \\
(2.90)\end{array}$ & $\begin{array}{c}-4.28^{*} \\
(7.52)\end{array}$ & \\
\hline Location & $\hat{\alpha}_{4}$ & $\begin{array}{l}-0.19 \\
(0.03)\end{array}$ & & & \\
\hline Wage rate & $\hat{\alpha}_{5}$ & $\begin{array}{c}-0.87 \\
(0.08)\end{array}$ & $\begin{array}{c}-0.87 \\
(0.09)\end{array}$ & $\begin{array}{l}-0.35 \\
(0.07)\end{array}$ & $\begin{array}{c}-0.33 \\
(0.10)\end{array}$ \\
\hline DLF & $\hat{\alpha}_{7}$ & & & & $\begin{array}{c}-0.55 \\
(0.13)\end{array}$ \\
\hline Price & $\hat{\alpha}_{6}$ & $\begin{array}{c}0.13 \\
(0.04)\end{array}$ & & & \\
\hline Gross profit for beverages & $\hat{\alpha}_{h}$ & & $\begin{array}{c}0.39 \\
(0.18)\end{array}$ & $\begin{array}{c}0.32 \\
(0.15)\end{array}$ & $\begin{array}{c}0.49 \\
(0.13)\end{array}$ \\
\hline Number of observations & & 131 & 101 & 101 & 202 \\
\hline Goodness of fit & & 0.992 & 0.933 & 0.931 & 0.945 \\
\hline
\end{tabular}

For the meaning of $\mathrm{NV}$ and EE see section 5.

The estimation results are produced by a non-linear least squares fit using Marquardt's algorithm [Marquardt, 1963]. No analytical expression is available for the standard error o. The standard error is computed numerically within the algorithm and it is assumed to be asymptotically normally distributed. Estimated standard errors $(\hat{\sigma})$ are printed beneath the estimated coefficient.

An asterisk (*) is printed next to coefficient $\hat{\eta}$ if $|\hat{\eta}|<1.98 \times \hat{\sigma}(\hat{\eta})$ i.e. if $\hat{\eta}$ is not significantly different from zero at a $5 \%$ level of significance.

The square of the correlation coefficient between the vector of $L_{i}$ and its estimation is taken as a measure of goodness of fit.

The following conclusions can be drawn from Table 1, regarding the above formulated hypotheses (only the columns of German hotels and of the Dutch hotels the columns NV and EE are considered).

H1: $\hat{\alpha}_{o}>0$ but not significantly in any one case. Consequently, the hypothesis that economies of scale can be obtained with respect to 
the use of labour is not supported for German standard hotels (of class 1) and small Dutch hotels. Nevertheless, $\hat{\alpha}_{o}$ does not differ significantly from 1.5 . If $\alpha_{0}$ is associated with labour involved in independently staffed service channels $\left(\alpha_{0}=\right.$ the number of independently staffed service channels $\times$ opening time $\div$ working time per employee), the value found for $\alpha_{0}$ is not unreasonable assuming that there is one independently staffed service channel and that the proportion of opening time to working time per employee equals three to two.

$\mathrm{H} 2$ : For the German sample $\hat{\alpha}_{\mathrm{o} 2}$ and $\hat{\alpha}_{\mathrm{o} 3}>0$ and significantly. The hypothesis that threshold labour depends on the class of the hotel is supported, and it is shown that, for these classes (related to luxury levels), there are economies of scale, and that they are much stronger for the higher class. For the Dutch sample $\hat{\alpha}_{\mathrm{o} 2}>0$ and significantly. Economies of scale can be obtained for larger hotels.

H3: For the German sample, $\hat{\alpha}_{11}, \hat{\alpha}_{12}$ and $\hat{\alpha}_{13}>0$ and significantly. For the Dutch samples, $\hat{\alpha}_{11}, \hat{\alpha}_{12}>0$ and significantly, but $\hat{\alpha}_{13}$ is not significantly different from zero.

For both Dutch samples the high standard errors for $\hat{\alpha}_{13}$ may be caused by multi-collinearity between variables.

Additional labour has to be attracted for the other sales in the German sample. Here one has to take into account that the other sales fraction includes the sales of subsidiary businesses (Nebenbetriebsertrag), which are typical in Germany, e.g. a Gasthof mit Metzgerei (a hotel with a butchery).

For both the German and the Dutch samples the sli's of the accommodation and restaurant fractions are significantly different from each other. The differing relative values are surprising.

H4: $\hat{\alpha}_{5}<0$ and significantly. Support is found for the hypothesis that the sli's decrease if the wage rate increases for both the German and Dutch samples.

The difference between the two Dutch samples is remarkable, although it should be said once again that for one sample the wage rate could only be approximated (cf. section 5).

H5: $\hat{\alpha}_{4}<0$ and significantly. Support is found for the hypothesis that the sli's depend on the type of location: the efficiency of labour in resort hotels is higher than in town hotels (due to longer stays and better predictability of required labour).

H6: $\hat{\alpha}_{6}<0$ and significantly for the German sample and Dutch samples. Support is found for the hypothesis that the sli's are higher when the luxury of the establishment increases.

Comparing the estimates of the columns of the respective legal structures $\mathrm{NV}$ and EE in Table 1, it is seen that there are no large differences disregarding the coefficient of the wage rate. We are not content with the estimates of $\alpha_{0}$ and $\alpha_{13}$ in the Dutch samples, because they are not significantly greater than zero, as is expected. Therefore, the Dutch 
samples are pooled to obtain smalier errors. It is also assumed that $\alpha_{13}=\alpha_{12}$ : restaurant sales and other sales are taken together. This can be done because it appeared in talks with managers that the other sales consisted mainly of selling activities of souvenirs etc., and rents from banquet activities. It appeared also that the former could be considered an idle time activity for the front office of the room department and that the latter demanded additional labour, which could be credited to the restaurant department. The importance of one activity compared to the other depends on the individual establishment. However, it is assumed that generally the influence of the latter activity on the volume of labour is of more importance. Therefore the other sales or remaining sales fractions are taken together with the restaurant sales.

A dummy variable is incorporated in equation (6.1) to permit the wage rate of the limited liability companies (NV) and family businesses (EE) to have different influences on labour intensities. The specification becomes:

$$
\begin{aligned}
\mathrm{L}_{\mathrm{i}}= & \alpha_{0}+\alpha_{02} \mathrm{D} 2_{\mathrm{i}}+\left(\alpha_{11} \mathrm{QA}_{\mathrm{i}}+\alpha_{12}\left(\mathrm{QR}_{\mathrm{i}}+\mathrm{QO}_{\mathrm{i}}\right)\right) \times \\
& \quad \exp \left(\alpha_{4} \mathrm{DL}\right) \times\left[\frac{\mathrm{LAB}_{\mathrm{i}}}{\overline{\mathrm{L}} \overline{\mathrm{A}} \overline{\mathrm{B}}}\right]^{\alpha_{5}+\alpha_{7} \mathrm{DLF}_{\mathrm{i}}} \times\left[\frac{\mathrm{LU}_{\mathrm{i}}}{\overline{\mathrm{L}} \overline{\mathrm{U}}}\right]^{\alpha_{\mathrm{t}}}+v_{\mathrm{i}}
\end{aligned}
$$

where

$\mathrm{DLF}=1$ when the establishment is a limited liability company (NV) and DLF $_{\mathrm{i}}=0$ otherwise (when the establishment is a family business (EE)).

The column total in Table 1 shows the results when the observations are grouped together. We see that:

(1) $\hat{\alpha}_{o}>0$, and again $\hat{\alpha}_{o}$ is not significantly different from zero, but again $\hat{\alpha}_{\mathrm{o}}$ does not differ significantly from 1.5 ;

(2) $\hat{\alpha}_{11}$ is significantly greater than $\hat{\alpha}_{12}$;

(3) $\hat{\alpha}_{7}<0$ and significantly; again a stronger influence of the wage rate is shown for the group of limited liability companies.

\section{CONCLUSIONS}

The following conclusions can be made:

First, the use of relation (6.1) to explain differences in labour productivity for groups of hotels is successful in our opinion for the following reasons.

- The explanation is high for a cross-section study (see goodness of fit in Table 1).

- Most of the coefficients show the expected sign and are significantly different from zero.

- The examination of the values of the residuals of both equations does not reveal any structure. No graph of the residuals can be published because of the secrecy of the data for both data files. 
- Economies of scale are shown for the German hotels of the classes of higher luxury levels and for the Dutch hotels with the higher values of annual sales. The idea that the larger hotels (which correspond with the hotels of higher luxury classes) require a higher threshold is supported and in the German case economies of scale increase with increasing luxury of the establishments.

- If the intercepts of the estimated relationships are interpreted in terms of number of independently staffed service channels, they seem reasonable. However, it is difficult to draw accurate conclusions because of the insignificance of $\hat{\alpha}_{o}$ and the lack of precise knowledge of opening times and number of independently staffed service channels.

Second, in the German sample, in which a clear distinction is made between the accommodation and restaurant sales, the partial scale adjusted labour intensities (partial sli's) differ significantly. Here the restaurant sli is significantly higher than the accommodation sli, which is a conceivable result. In the Dutch sample, however, the inverse result is found. This might be caused by a different partitioning of sales.

Third, strong influence of the wage rate per establishment is shown. In the German sample a value of -0.9 is found for the elasticity of the sli's with respect to the wage rate. For the Dutch businesses different values are found for the respective groups of legal structures: for the group of limited liabilities (with all the persons employed on the payroll so that the wage rate can be computed) a value of -0.9 is found; for the group of family businesses (with a payroll for the persons employed excluding the family labour) the wage rate has been approximated and the value of -0.35 is found. Values ranging from -0.2 to -0.8 are estimated in retail studies. ${ }^{13}$

Fourth, the influence of location is shown in the German sample: the scale adjusted labour intensity is significantly lower for resort hotels compared to town hotels. In a tourist location the sli is about 20 per cent lower. This means that an (additional) amount of sales demands more labour in a town hotel than in a resort hotel.

Fifth, the empirical estimation of the influences enables us not only to test the plausibility of the hypotheses, but also to quantify the intensity of the (sometimes straightforward) influences.

In view of the experiences of similar studies in retailing, it is reasonable to assume that the results do not specifically apply to a German or Dutch sample. Similar results are expected in other countries. This would be an interesting subject for further study.

\section{NOTES}

1. See Nooteboom [1982] for a theoretical explanation based on queueing theory and Nooteboom [1980] for empirical evidence. See also Thurik [1984] for empirical evidence concerning large retail establishments.

2. See Van der Hoeven [1982]. In this study an expression of McClelland is paraphrased 
that retailing and hotel and catering business both provide utilities of form, place, time and convenience. A similar statement by $\mathrm{C}$. $\mathrm{H}$. Lovelock, that a consumer evaluates service by its form, place, time, psychic and monetary utility is used by R.S. Lewis in 'Marketing Positioning for Hotels', Cornell Hotel and Restaurant Administration Quarterly, Vol. 22, No. 1.

3. See Nooteboom [1980], Thurik and Van der Wijst [1982] and Thurik [1984].

4. For one-department shops Nooteboom has justified the linear relationship (2.1) using queueing theory. Its extension to shops with more departments is not straightforward in our view in spite of the encouraging aspects mentioned below.

Jackson [1969] did considerable research on queueing networks. His decomposition theorem gives sufficient conditions under which a general network of queues may be treated as an aggregation of independent queues. The main conditions are that customers in the system are routed randomly and service discipline is not a function of a customer's service time or his routing through the system. Hillier and Lieberman [1980] state that in a theoretical network (with a Poisson input and exponential service times) it can be proved that each service facility has a Poisson input. The total expected waiting time and the expected number of customers in the entire system can then be obtained by merely summing up the corresponding quantities obtained at the respective facilities. However, this statement is not valid for systems with only finite queues, which Hillier and Lieberman describe as systems where the upper bound is small enough so that it actually would be reached with some frequency. We leave the validity of the assumption that large establishments can be considered as a system of several independent small establishments, without further investigation.

5. See Inter-firm comparative survey [Bureau of Financial Analysis, 1978] and Maschke [1979] and Maschke [1981].

6. See Inter-firm comparative survey [Bureau of Financial Analysis, 1978] and Trends in the Hotel Business [1979].

7. See Nooteboom [1980], Thurik and Van der Wijst [1982] and Thurik [1984].

8. See 'Pricing in Hotels', a contribution of H. Anthea Rogers in Kotas [1980].

9. The author acknowledges the assistance of the CBS, in particular M. Booleman of the Department of Commercial Services.

10. A description of the details of this computation is beyond the scope of this article.

11. See Produktiestatistieken Commerciële Handel en Dienstverlening 1977/1978 [CBS, 1980: 23].

12. A disturbance term is defined as an independently distributed stochastic variable with zero expectation and constant variance.

13. See Nooteboom [1980], Thurik and Van der Wijst [1982] and Thurik [1984].

\section{REFERENCES}

Bureau of Financial Analysis, 1978, Inter-firm Comparative Survey: The Hotel Industry in South Africa 1977/78, Report No. B18, Pretoria: Bureau of Financial Analysis of the University of Pretoria.

Central Bureau of Statistics, 1980, Produktiestatistieken Commerciële Dienstverlening Hotels 1977 en 1978, The Hague: Staatsuitgeverij.

Hillier, F.S. and Lieberman, G. J., 1980, Introduction to Operations Research, San Francisco: Holden-Day Inc.

Jackson, J.R., 1969, 'Jobshop-like Queueing Systems', Management Science. Vol. 10. pp. 131-42.

Kotas, R. (ed.), 1975, Market Orientation in the Hotel and Catering Industry, London: Surrey University Press in associaton with Intertext Publishing Limited.

Kotas, R. (ed.), 1980, Managerial Economics for Hotel Operation, London: Surrey University Press.

Lewis, R. S., 1981, 'Market Positioning for Hotels', Cornell Hotel and Restaurant Administration Quarterly, Vol. 22, No. 1. 
Marquardt, D. W., 1963, 'An Algorithm for Least Squares Estimation of Non-Linear Parameters', Journal of the Society for Industrial and Applied Mathematics, Vol. 11, pp.431-41.

Maschke, J., 1979, Hotelbetriebsvergleich 1977, Munich: Deutsches Wirtschaftswissenschaftliches Institut für Fremdenverkehr an der Universität München (DWIF).

Maschke, J., 1981, Hotelbetriebsvergleich 1979, Munich: DWIF.

Nooteboom, B., 1980, Retailing: Applied Analysis in the Theory of the Firm, Uithoorn Amsterdam: Gieben.

Nooteboom, B., 1982, 'A New Theory of Retailing Costs', European Economic Review, Vol. 17, pp.163-86.

Trends in the Hotel Business, 1979, 1980, International edition, New York: Pannell, Kerr, Forster \& Company and Harris, Kerr, Forster \& Company.

Thurik, A. R., 1984, 'Labour Productivity, Economies of Scale and Opening Time in Large Retail Establishments', Service Industries Journal, Vol. 4, No. 1.

Thurik, A.R. and Van der Wijst, D., 1982, 'Part-time Labour and Labour Productivity in Retailing', Research Paper EIM 8205, The Hague: Research Institute for Small and Medium Sized Businesses.

Van der Hoeven, W.H.M., 1982, 'A Labour Cost Curve in the Hospitality Business', Research Paper EIM 8202, The Hague: Research Institute for Small and Medium Sized Businesses.

White, J. A. (ed.), 1975, Analysis of Queueing Systems, London: Academic Press. 
Copyright of Service Industries Journal is the property of Taylor \& Francis Ltd and its content may not be copied or emailed to multiple sites or posted to a listserv without the copyright holder's express written permission. However, users may print, download, or email articles for individual use. 